\title{
Impaired Hepatic Glycogen Synthesis in Glucokinase-deficient (MODY-2) Subjects
}

\author{
Gilberto Velho, ${ }^{\star}$ Kitt Falk Petersen, Gianluca Perseghin, Jong-Hee Hwang, Douglas L. Rothman, Maria E. Pueyo, ${ }^{*}$ \\ Gary W. Cline, Philippe Froguel, ${ }^{\ddagger}$ and Gerald I. Shulman \\ Department of Internal Medicine, Yale University School of Medicine, New Haven, Connecticut 06520-8020; and *INSERM U358, \\ Hôpital Saint-Louis, Paris, France CNRS EP10, ${ }^{\ddagger}$ Institut Pasteur and CHU, Lille, France
}

\begin{abstract}
All glucokinase gene mutations identified to date have been localized to exons that are common to the pancreatic and hepatic isoforms of the enzyme. While impaired insulin secretion has been observed in glucokinase-deficient subjects the consequences of this mutation on hepatic glucose metabolism remain unknown. To examine this question hepatic glycogen concentration was measured in seven glucokinasedeficient subjects with normal glycosylated hemoglobin and 12 control subjects using ${ }^{13} \mathrm{C}$ nuclear magnetic spectroscopy during a day in which three isocaloric mixed meals were ingested. The relative fluxes of the direct and indirect pathways of hepatic glycogen synthesis were also assessed using $\left[1-{ }^{13} \mathrm{C}\right]$ glucose in combination with acetaminophen to noninvasively sample the hepatic UDP-glucose pool. Average fasting hepatic glycogen content was similar in glucokinasedeficient and control subjects $(279 \pm 20$ vs $284 \pm 14 \mathrm{mM}$; mean \pm SEM), and increased in both groups after the meals with a continuous pattern throughout the day. However, the net increment in hepatic glycogen content after each meal was 30-60\% lower in glucokinase-deficient than in the control subjects (breakfast, $46 \%$ lower, $P<0.02$; lunch, $62 \%$ lower, $P=0.002$; dinner; $30 \%$ lower, $P=0.04$ ). The net increment over basal values $4 \mathrm{~h}$ after dinner was $105 \pm 18 \mathrm{mM}$ in glucokinase-deficient and $148 \pm 11 \mathrm{mM}$ in control subjects $(P=0.04)$. In the $4 \mathrm{~h}$ after breakfast, flux through the gluconeogenic pathway relative to the direct pathway of hepatic glycogen synthesis was higher in glucokinase-deficient than in control subjects $(50 \pm 2 \%$ vs $34 \pm 5 \% ; P=0.038)$. In conclusion glucokinase-deficient subjects have decreased net accumulation of hepatic glycogen and relatively augmented hepatic gluconeogenesis after meals. These results suggest that in addition to the altered $\beta$ cell function, abnormalities in liver glycogen metabolism play an important role in the pathogenesis of hyperglycemia in patients with glucokinase-deficient maturity onset diabetes of young. $(J$. Clin. Invest. 1996. 98:1755-1761.) Key words: glucokinase • hepatic glycogen • gluconeogenesis • nuclear magnetic resonance $\bullet$ glucokinase gene mutations
\end{abstract}

Address correspondence to Gerald I. Shulman, M.D., Ph.D., Yale University School of Medicine, Department of Internal Medicine, Fitkin 1, P.O. Box 20820, New Haven, CT 06520-8020. Phone: 203-785-5447; FAX: 203-785-6015; E-mail: Gerald_Shulman@QM.yale.edu

Received for publication 17 May 1996 and accepted in revised form 30 July 1996.

J. Clin. Invest.

(C) The American Society for Clinical Investigation, Inc.

0021-9738/96/10/1755/07 \$2.00

Volume 98, Number 8, October 1996, 1755-1761

\section{Introduction}

Non-insulin-dependent diabetes mellitus (NIDDM) ${ }^{1}$ is a genetically, metabolically, and clinically heterogeneous disorder of glucose homeostasis characterized by defects in the secretion and action of insulin. Genetic investigations in families with strong diabetes aggregation have demonstrated that mutations in the coding regions of the glucokinase gene (GCK) on chromosome 7 result in a familial subtype of NIDDM, characterized by an early age of onset and autosomal dominant inheritance with high penetrance (maturity onset diabetes of young 2 [MODY 2]) (1-6). Glucokinase phosphorylates glucose to glucose-6-phosphate and plays a major role in the regulation and integration of glucose metabolism in pancreatic $\beta$ cells and hepatocytes $(7,8)$. The enzymatic activity of mutant glucokinase was shown in vitro to vary according to the nature and position of the mutation, ranging from no activity at all to a slight decrease in the $\mathrm{V}_{\max }$ of the enzyme and its affinity for glucose $(9,10)$. Impairment in the enzymatic activity of mutant glucokinase results in decreased glycolytic flux in the $\beta$ cell (8, 11) which translates in vivo as a glucose sensitivity defect leading to a right shift in the dose-response curve of glucoseinduced insulin secretion $(12,13)$.

All GCK mutations associated with hyperglycemia that have so far been identified have been localized to exons that are common to both the pancreatic and hepatic isoforms of the enzyme (1-6). It is therefore certain that the hepatocytes also express the mutant enzyme, although the consequences of these mutations on the hepatic metabolism of glucose, and their role in the pathogenesis of hyperglycemia remain unknown. Glucose is taken up by the liver after a meal and stored as glycogen, a metabolic process that involves glucose phosphorylation by glucokinase. Alterations in hepatic glycogen synthesis directly resulting from the decreased glucokinase activity in the liver might therefore contribute to the postprandial hyperglycemia of glucokinase-deficient subjects. If so, this would be the first demonstration of a primary hepatic defect leading to NIDDM.

Recent developments in ${ }^{13} \mathrm{C}$ nuclear magnetic resonance (NMR) spectroscopy have made it possible to measure hepatic glycogen content in humans noninvasively $(14,15)$. This technique was used in the present study to measure changes in net hepatic glycogen concentration in glucokinase-deficient and normoglycemic control subjects throughout a day in which three isocaloric mixed meals were ingested. Hepatic glycogen synthesis may follow two distinct metabolic pathways, namely, a direct or glucokinase-dependent (glucose $\rightarrow$ glucose-6-phosphate $\rightarrow$ glucose-1-phosphate $\rightarrow$ UDP-glucose $\rightarrow$ glycogen)

1. Abbreviations used in this paper: GCK, glucokinase gene; NIDDM, non-insulin-dependent diabetes mellitus; NMR, nuclear magnetic resonance. 
and an indirect or gluconeogenic (3-carbon units $\rightarrow \rightarrow$ phosphoenolpyruvate $\rightarrow \rightarrow$ glucose-6-phosphate $\rightarrow$ glucose-1phosphate $\rightarrow$ UDP-glucose $\rightarrow$ glycogen) pathways. In normal subjects fasted overnight both pathways contribute equally to hepatic glycogen synthesis during a glucose infusion (16). However, as glucokinase deficiency is expected to primarily affect the flux of the direct pathway, we assessed the relative contribution of the two pathways to the net hepatic glycogen synthesis. This was done by adding $\left[1-{ }^{13} \mathrm{C}\right]$ glucose in the meal in combination with acetaminophen to noninvasively sample the UDP-glucose pool (16).

\section{Methods}

Subjects. Seven Caucasian glucokinase-deficient men from four kindreds were studied. These kindreds belong to a cohort of multiplex NIDDM families collected all over France (1), and responded to the criteria of MODY: presence of non-insulin dependent chronic hyperglycemia with early age of onset (before $25 \mathrm{yr}$ ) at least in two consecutive generations (17). Mutations in these individuals are: a glutamic acid-279 < amber in kindred F8, a glycine-261 < arginine in kindred F390, a glutamine- $98<$ amber in kindred F393, and a valine-203 < alanine in kindred F422 (1). The glucose tolerance status of affected individuals was evaluated by a 2 -h oral glucose ( 75 grams) tolerance test (OGTT). They presented either with diabetes $(n=5)$ or impaired glucose tolerance (IGT; $n=1$ ) according to the World Health Organization definition (18) or with mild fasting hyperglycemia $(n=$ 1 ). Mild fasting hyperglycemia was defined as a fasting plasma glucose concentration between 6.1 and $7.7 \mathrm{mmol} /$ liter on two separate measurements and a OGTT $2 \mathrm{~h}$ plasma glucose concentration $<7.8$ $\mathrm{mmol} /$ liter. A fasting plasma glucose concentration $>6.1 \mathrm{mmol} / \mathrm{liter}$ represents a value two to three standard deviations above the mean of the normal French population (19). Apart from chronic hyperglycemia, all subjects were in good general health, according to physical examination and routine blood and urine biochemical screening. No subject had proteinuria or raised serum creatinine. Two subjects were taking a sulfonylurea as a treatment for diabetes, and the drug was discontinued $7 \mathrm{~d}$ before the study, while the other subjects received no medication. 12 lean, healthy Caucasian men with similar age and weight and with no diabetic relatives were used as a control group. Data from eight of the control subjects were reported in a previous study (20). Basic demographic and clinical profile of subjects and controls are shown in Table I. Written consent was obtained from all par- ticipants after explanation of the purpose, nature, and potential risks of the study. The protocol was approved by the Human Investigation Committee of Yale University School of Medicine (New Haven, CT).

Study design. Subjects were admitted to the Yale/New Haven Hospital Clinical Research Center $4 \mathrm{~d}$ before the study to normalize their sleep patterns and diet. For the following $3 \mathrm{~d}$ before the study and during the two study days (inpatient days 4 and 5) the subjects ingested a weight maintenance diet ( $35 \mathrm{kcal} / \mathrm{kg}$ per day), which was prepared by the Clinical Research Center metabolic kitchen. The proportion of calories was divided according to the American Diabetes Association guidelines: $60 \%$ carbohydrate, $20 \%$ protein, and $20 \%$ fat, and the calories were distributed equally among the three meals with no snacks given between the meals.

On the first study day (inpatient day 4) subjects underwent ${ }^{13} \mathrm{C}$ NMR measurements of hepatic glycogen content. The basal hepatic glycogen concentration was measured at 7:00 a.m. before breakfast. Subjects had their breakfast at 8:00 a.m., lunch at 1:00 p.m., and dinner at 6:00 p.m. following the same schedule as the previous $3 \mathrm{~d}$. Meals were consumed completely within $20 \mathrm{~min}$. NMR measurements of hepatic glycogen were performed continuously in 30-min blocks starting $\sim 2 \mathrm{~h}$ after each meal and continuing just before the next meal to capture the greatest increment in hepatic glycogen concentration.

To minimize subject motion during the NMR measurements, which would have reduced the quality of the glycogen spectra, blood sampling was performed on the second study day (inpatient day 5). At 6:00 a.m. a catheter was inserted into an antecubital vein for blood sampling and the subjects ingested the identical diet at the same times as they did on the first study day. Blood samples were obtained before each meal and every 15 min thereafter for the measurement of plasma glucose and ${ }^{13} \mathrm{C}$-glucose enrichment and every $30 \mathrm{~min}$ for insulin, C-peptide and glucagon. To evaluate the contributions of the direct and indirect pathways to hepatic glycogen synthesis, 10 grams of $\left[1-{ }^{13} \mathrm{C}\right]$ glucose ( $99 \%$ enriched) was substituted for 10 grams of glucose in the breakfast and administered along with $300 \mathrm{mg}$ of acetaminophen to each subject (16). Urine was collected at hourly intervals after breakfast for assessment of ${ }^{13} \mathrm{C}$ enrichment in the acetaminophen glucuronide.

In vivo ${ }^{13} C$ NMR spectroscopy. All measurements were performed in a 2.1-T 1m-bore spectrometer (Biospec; Bruker, Billerica, MA) as previously described (14). Briefly, a 9 -cm circular ${ }^{13} \mathrm{C}$ coil was used as transmitter/receiver coil and a $12 \times 14-\mathrm{cm}$ butterfly proton coil was used for shimming, scout images, and proton decoupling during ${ }^{13} \mathrm{C}$ NMR acquisitions. The liver position in the supine subject was confirmed from a multislice axial FLASH image (21). Signals from

Table I. Demographic and Clinical Profile of GCK-deficient and Control Subjects

\begin{tabular}{|c|c|c|c|c|c|c|c|c|c|}
\hline Subject & Kindred & Age & BMI & $\begin{array}{c}\text { Glucose } \\
\text { tolerance } \\
\text { status* }\end{array}$ & $\begin{array}{c}\text { Age of } \\
\text { diagnosis }\end{array}$ & $\begin{array}{l}\text { Glycosylated } \\
\text { hemoglobin }\end{array}$ & $\begin{array}{l}\text { Glucose } \\
0 \mathrm{~min}^{\ddagger}\end{array}$ & $\begin{array}{l}\text { Glucose } \\
120 \mathrm{~min}^{\ddagger}\end{array}$ & Treatment \\
\hline & & $y r$ & $k g / m^{2}$ & & $y r$ & $5.9-8.2 \%$ & $m M$ & $m M$ & \\
\hline A (JNO) & F393 & 39 & 24.6 & $\mathrm{DM}$ & 28 & 7.2 & 9.1 & 11.2 & Sulfonylurea \\
\hline B (GVI) & F422 & 40 & 22.8 & $\mathrm{DM}$ & 29 & 7.7 & 8.3 & 8.5 & Sulfonylurea \\
\hline $\mathrm{C}(\mathrm{SVI})$ & F422 & 20 & 19.8 & MFH & 13 & 7.4 & 6.1 & 5.7 & none \\
\hline $\mathrm{D}(\mathrm{APE})$ & F390 & 47 & 24.2 & $\mathrm{DM}$ & 28 & 8.2 & 6.9 & 11.5 & none \\
\hline $\mathrm{E}(\mathrm{NPE})$ & F390 & 19 & 20.2 & DM & 10 & 8.4 & 6.9 & 13.9 & none \\
\hline $\mathrm{F}(\mathrm{GNO})$ & F393 & 24 & 21.6 & IGT & 7 & 7.8 & 6.6 & 8.8 & none \\
\hline $\mathrm{G}(\mathrm{SBE})$ & F8 & 20 & 19.4 & DM & 17 & 6.8 & 6.6 & 11.2 & none \\
\hline \multicolumn{2}{|c|}{ Subjects $(\mathrm{m} \pm \mathrm{SE})$} & $30 \pm 5$ & $21.8 \pm 0.8$ & & $19 \pm 3$ & $7.6 \pm 0.2$ & $7.2 \pm 0.4$ & $10.1 \pm 1.0$ & \\
\hline \multicolumn{2}{|c|}{ Control group $(\mathrm{m} \pm \mathrm{SE})$} & $24 \pm 1$ & $23.6 \pm 0.3$ & & - & - & $5.0 \pm 0.1$ & - & \\
\hline
\end{tabular}

*MFG, IGT, and DM stand, respectively, for mild fasting hyperglycemia, impaired glucose tolerance, and diabetes mellitus. ${ }^{*}$ Plasma glucose during an oral glucose (75 grams) tolerance test. 
the liver were acquired by image selected in vivo spectroscopy localization technique to remove signals from surface above the liver (22). A 4-ms hyperbolic secant pulse was used to invert the $2.5 \mathrm{~cm}$ of the skin surface, and as a result, signals from the surface were eliminated by adding scans with an alternate inverse pulse (23). A $180^{\circ}$ pulse at the coil center was used as an excitation pulse. This pulse was calibrated each time using a 2-cm sphere containing ${ }^{13} \mathrm{C}$-enriched formic acid that was placed at coil center. Each proton decoupled ${ }^{13} \mathrm{C}$ NMR spectrum consisted of 12,800 scans that were acquired for $30 \mathrm{~min}$. All spectra were processed and analyzed in an identical fashion. Hepatic glycogen was quantified by integration of the $\mathrm{C} 1$ glycogen peak at $100.5 \mathrm{ppm}$ with a computer (Aspect 3000; Bruker) using the same frequency bandwidth for all spectra $(250 \mathrm{~Hz})$. Absolute quantitation of hepatic glycogen was determined by comparing the peak integral of the $\mathrm{C} 1$ liver glycogen peak with the $\mathrm{C} 1$ glycogen peak integral of a glycogen standard taken under identical conditions. Finally, minor corrections $(<10 \%)$ were made for incomplete space filling of the surface coil by the liver by comparison of the axial image of the glycogen phantom with that of the subjects' liver.

Analytical procedures. Plasma glucose concentration was determined by the glucose oxidase method (Glucose Analyzer II; Beckman Instruments, Fullerton, CA). Plasma immunoreactive insulin, C-peptide, and glucagon were measured with double antibody radioimmunoassay techniques using commercially available kits (insulin; Diagnostic Systems Laboratories, Webster, TX, C-peptide; Diagnostic Products Corp., Los Angeles, CA, and glucagon; ICN Biomedicals Inc., Costa Mesa, CA). Glycosylated hemoglobin was measured using an ion exchange chromatography method (Isolab, Akron, $\mathrm{OH}$ ). The relative contributions of the direct and indirect pathways to hepatic glycogen synthesis were determined using acetaminophen to noninvasively sample the hepatic UDP-glucose pool as previously described (16). Briefly, plasma samples were deproteinized with $\mathrm{Ba}(\mathrm{OH})_{2}$ and $\mathrm{ZnSO}_{4}$ and deionized by passage through a mixed bed ion exchange resin column. After evaporation, the residual glucose
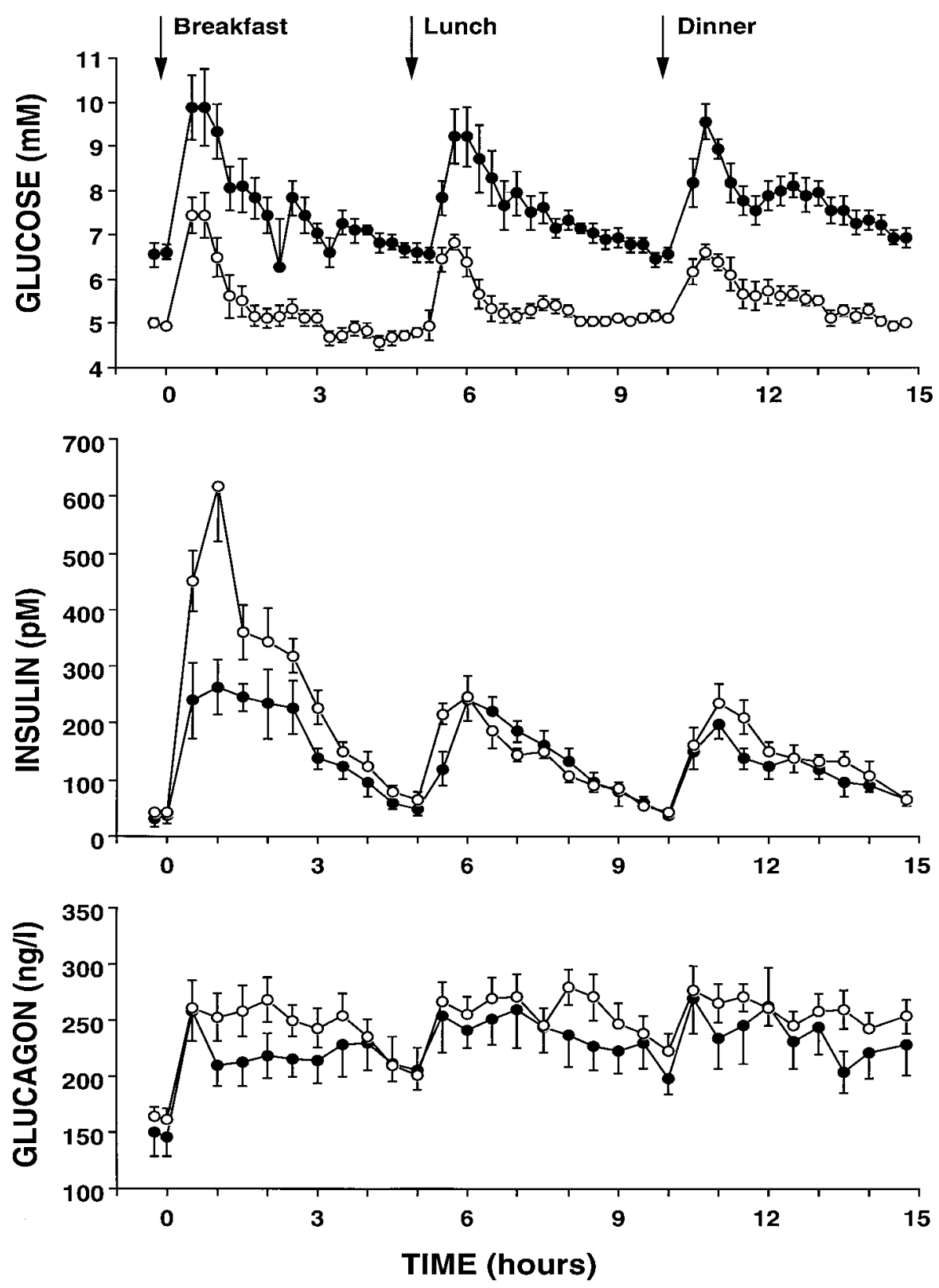

Figure 1. Time course for plasma glucose, insulin, and glucagon concentrations in glucokinase-deficient (closed symbols) and control (open symbols) subjects during the second study day in which three isocaloric mixed meals were ingested $5 \mathrm{~h}$ apart. 
was derivatized with pyridine/acetic anhydride (1:2 in volume) to yield glucose pentaacetate. Total ${ }^{13} \mathrm{C}$ enrichment of plasma glucose was determined by chemical ionization mass spectral analysis of the pentaacetate glucose derivative performed on a gas chromatographymass spectrometer (HP 5971 GC-MS; Hewlett Packard Co., Palo Alto, CA) (24). Urine acetaminophen-glucuronide was semipurified by anion exchange chromatography. After freeze-drying, the sample was redissolved in a minimum volume of water, deproteinized with sodium sulfate and methanol, and filtered. The solvent was removed on a rotovapor (Buchi, Westbury, NY). Urinary acetaminophen-glucuronide ${ }^{13} \mathrm{C}$ enrichment was determined by both gas chromatography-mass spectrometry and ${ }^{13} \mathrm{C}$ NMR spectroscopy. The isolated and purified acetaminophen-glucuronide was placed in a 5-mm NMR tube, and ${ }^{13} \mathrm{C}$ NMR spectroscopy was performed at $125.76 \mathrm{MHz}$ (AM500; Bruker). NMR chemical shifts of the glucuronide $\mathrm{C} 1, \mathrm{C} 2$, and $\mathrm{C} 6$ were assigned to $101.0,73.2$, and $176.1 \mathrm{ppm}$, respectively. In the acetaminophen moiety, $\mathrm{C}^{\prime}\left(\mathrm{C}^{\prime}\right)$ and $\mathrm{C} 3\left(\mathrm{C}^{\prime}\right)$ of the aromatic ring were assigned to 117.7 and $123.8 \mathrm{ppm}$. The percent of glycogen synthesized by the direct pathway was calculated by the following equation: percent of Direct Pathway = C1-C6 acetaminophen-glucuronide/C1-C6 plasma glucose, where $\mathrm{C} 1, \mathrm{C} 6$ acetaminophen-glucuronide and $\mathrm{C} 1$, C6 plasma glucose represent the ${ }^{13} \mathrm{C}$ enrichment in the $\mathrm{C} 1$ and $\mathrm{C} 6$ positions of the glucuronide and plasma glucose, respectively.

Data analyses. All values are expressed as mean \pm standard error. Areas under the plasma insulin and glucagon curves were calculated by the trapezoidal rule with data from $0-5 \mathrm{~h}$ after each meal. Repeated measures ANOVA were used when comparing glucose and glucagon levels over time after meals and when comparing the mean relative flux of the direct pathway for hepatic glycogen synthesis after breakfast. Peak glucose levels and other comparisons between groups are unpaired Student's $t$ test. Statistics were performed with the JMP software (SAS Institute Inc., Cary, NC).

\section{Results}

Time courses for mean plasma glucose, insulin, and glucagon concentration during the second study day (inpatient day 5) are shown in Fig. 1. Fasting plasma glucose was significantly higher in glucokinase-deficient than in control subjects $(6.6 \pm 0.2$ vs $5.0 \pm 0.1 \mathrm{mM} ; P=0.0001)$, and remained significantly higher throughout the day (ANOVA, $P=0.0001$ after each meal). The peak plasma glucose concentration was observed $45 \mathrm{~min}$ after each of the meals and was $9.9 \pm 0.9$ vs $7.4 \pm 0.5 \mathrm{mM}(P=$ $0.015)$ following breakfast, $9.2 \pm 0.5$ vs $6.8 \pm 0.2 \mathrm{mM}(P=$ $0.0002)$ after lunch, and $9.6 \pm 0.4$ vs $6.6 \pm 0.2 \mathrm{mM}(P=0.0001)$ following dinner, respectively, in glucokinase-deficient and control subjects.

Fasting plasma insulin was not significantly different in glucokinase-deficient $(30 \pm 9 \mathrm{pM})$ and control subjects $(42 \pm 5$ $\mathrm{pM})$. One hour after the ingestion of breakfast, plasma insulin peaked at $264 \pm 43 \mathrm{pM}$ in patients and $618 \pm 99 \mathrm{pM}$ in controls $(P<0.03)$. The area under the insulin curve $(0-5 \mathrm{~h})$ expresses the overall insulin secretory response after breakfast: and was $48,690 \pm 6,674 \mathrm{pM} / \mathrm{min}$ vs $79,494 \pm 7,261 \mathrm{pM} / \mathrm{min}(P=0.01)$, in patients and control subjects, respectively. Three and a half hours after breakfast plasma insulin concentration was again similar in glucokinase-deficient and control subjects and remained similar throughout the day. Insulin concentration peaked $1 \mathrm{~h}$ after lunch at $240 \pm 36 \mathrm{pM}$ in glucokinase-deficient subjects and $246 \pm 38 \mathrm{pM}$ in controls, and $1 \mathrm{~h}$ after dinner at $198 \pm 27$ in glucokinase-deficient subjects and $234 \pm 32 \mathrm{pM}$ in controls. Insulin areas under the curve were also similar in glucokinase-deficient subjects and controls after lunch $(5-10 \mathrm{~h})$ $38,904 \pm 4,318$ vs $38,808 \pm 2,207 \mathrm{pM} / \mathrm{min}$ and dinner (10-15 h); $34,272 \pm 4,608$ vs $41,520 \pm 3,966 \mathrm{pM} / \mathrm{min}$ after dinner. Similar

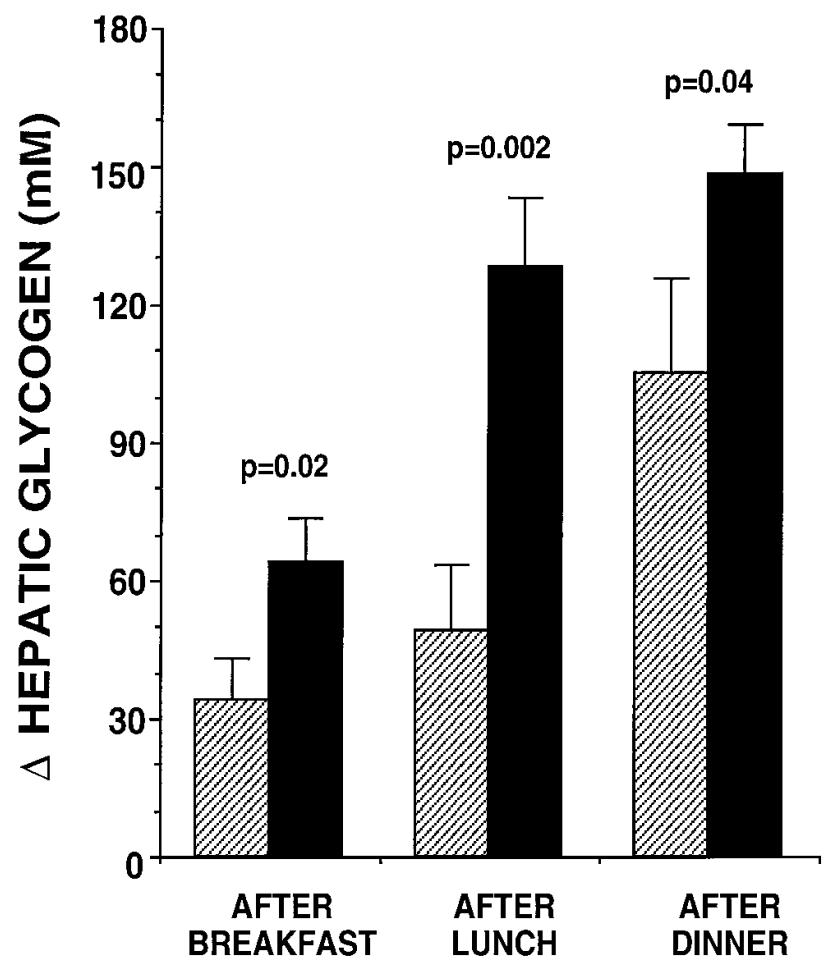

Figure 2. Increment in hepatic glycogen concentration over basal values after breakfast, lunch, and dinner in glucokinase-deficient (hatched bars) and control (closed bars) subjects obtained 4-5 h after the meal.

profiles of plasma glucagon were observed in both groups throughout the day (Fig. 1).

Average fasting hepatic glycogen concentration was similar in glucokinase-deficient and control subjects (279 \pm 20 vs $284 \pm 14 \mathrm{mM}$ ), and in both groups it increased after the meals with a continuous pattern throughout the day. However, the mean increment in hepatic glycogen content after each meal was typically $30-60 \%$ lower in the glucokinase-deficient subjects compared with the control subjects (breakfast, $46 \%$ lower, $P<0.02$; lunch, $62 \%$ lower, $P<0.002$; dinner, $30 \%$ lower, $P=0.04$ [Fig. 2]). Peak hepatic glycogen concentration $4 \mathrm{~h}$ after breakfast, lunch, and dinner was $313 \pm 20$ vs $347 \pm 14$ $\mathrm{mM}(P=0.17), 333 \pm 22$ vs $414 \pm 17 \mathrm{mM}(P=0.02)$, and $383 \pm 16$ vs $434 \pm 14 \mathrm{mM}(P=0.04)$, respectively in glucokinase-deficient and control subjects.

The mean relative flux of the direct pathway for hepatic glycogen synthesis after breakfast is shown in Fig. 3. During the second hour after breakfast (1-2-h interval) the relative flux through the direct pathway was significantly less in the glucokinase-deficient subjects than in controls $(36 \pm 3$ vs $55 \pm 4 \%$; $P=0.007)$. Flux through the direct pathway increased in both

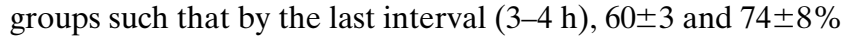
of hepatic glycogen was synthesized by the direct pathway in glucokinase-deficient and control subjects, respectively. Assuming linear rates of hepatic glycogen synthesis over the $4 \mathrm{~h}$ after breakfast, it can be estimated that glucokinase-deficient subjects synthesized $50 \pm 2 \%$ of their hepatic glycogen during this time by the direct pathway compared with $66 \pm 5 \%(P<$ 0.04 ) for the control subjects. (Repeated measures ANOVA taking into account the 1-2-, 2-3-, and 3-4-h intervals: $P=$ 0.038). 


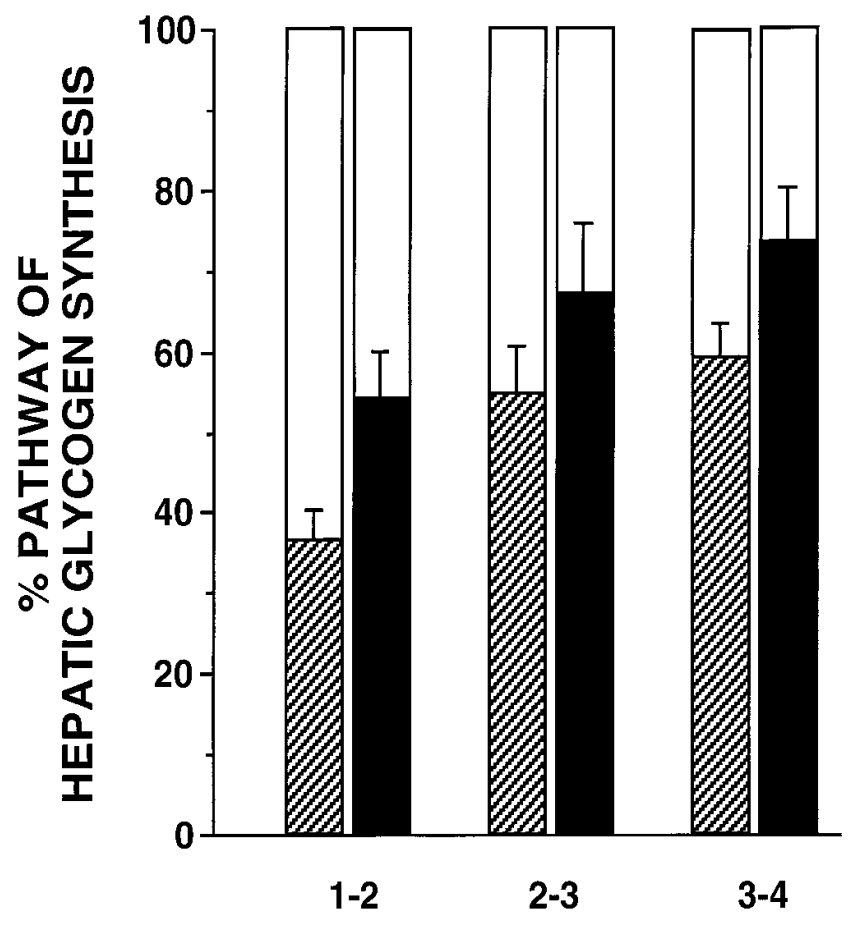

HOURS AFTER BREAKFAST

Figure 3. Relative fluxes of the direct and indirect pathways of hepatic glycogen synthesis determined at 1-h intervals after breakfast in glucokinase-deficient and control subjects. Hatched and closed bars represent the percentage of hepatic glycogen synthesized by the direct pathway in glucokinase-deficient and control subjects, respectively. Open bars represent the percentage of hepatic glycogen synthesized by the indirect pathway in each group. Statistical difference $(P=0.038)$ between groups was assessed by repeated measures ANOVA taking into account the 1-2, 2-3, and 3-4 h intervals.

\section{Discussion}

We have examined the net hepatic glycogen synthesis in glucokinase-deficient and control subjects throughout the course of a day in which three mixed isocaloric meals were ingested. The results showed a decreased accumulation of hepatic glycogen throughout the day in glucokinase-deficient as compared to control subjects. This defect was observed not only after breakfast, when glucokinase-deficient subjects presented with reduced plasma insulin concentrations, but also following lunch and dinner in the presence of similar plasma insulin and glucagon concentrations. This observation suggests that the defect in hepatic glycogen synthesis is indeed related to the decreased enzymatic activity of mutant GCK, and not to an acquired alteration of hepatic glucose metabolism, as we have observed in subjects with poorly controlled insulin dependent diabetes mellitus (20). Five hours after dinner, the increment over basal values of net glycogen concentration in glucokinasedeficient subjects was $70 \%$ of the increment observed in the control subjects. Considering that the glucokinase-deficient subjects had significantly higher plasma glucose concentrations throughout the day compared with the control subjects implies an even lower efficiency of hepatic glycogen synthesis in terms of glucose availability than the control subjects. On the other hand, considering that the enzymatic activity of the proteins encoded by these mutant GCK alleles is negligible (between 0 and $0.5 \mathrm{U} / \mathrm{mg}$ as compared with $100 \mathrm{U} / \mathrm{mg}$ for the wild type glucokinase) (9) one might have expected to observe in these subjects an even more severe reduction in net glycogen accumulation. Several factors might have contributed to attenuate this defect. Since all these glucokinase-deficient subjects are heterozygous for the mutant alleles, they are predicted to have glucokinase levels that are at least $50 \%$ of normal. It has been recently shown that there might be an overexpression of the normal allele of the pancreatic isoform in carriers of GCK mutations that severely impair the activity of the enzyme (11). The expression of pancreatic and hepatic isoforms are controlled by different mechanisms. In the $\beta$-cell the GCK promoter is regulated by glucose at the posttranscriptional level $(7,25)$. The hepatic isoform of GCK has a different promoter, which has the potential to up-regulate the expression of the alleles in response to insulin $(7,26)$. Recent data in transgenic mice generated by homologous recombination showed that heterozygous disruption of GCK gene results only in 37 and $28 \%$ reduction of glucokinase activity in the pancreas and liver, respectively (27). Discordant results were obtained in transgenic mice generated by homologous recombination regarding the effect of heterozygous disruption of GCK on glucokinase activity. In one report, investigators observed only a 37 and $28 \%$ reduction of glucokinase activity in the pancreas and liver, respectively (27), while other investigators reported a more significant effect: $44 \%$ reduction of glucokinase activity in the liver (28) and a $42 \%$ (28) to $50 \%$ (29) reduction in the pancreas. Based on all these results we may speculate that there could also be an overexpression of the normal GCK allele not only in the $\beta$-cells but also in the hepatocytes of these heterozygous glucokinase-deficient subjects.

The gluconeogenic pathway was relatively more important for synthesizing hepatic glycogen in the glucokinase-deficient subjects. In the first $2 \mathrm{~h}$ after breakfast $>60 \%$ of the glycogen was derived from gluconeogenesis in the glucokinase-deficient subjects compared with $<50 \%$ in the control subjects. The percentage of hepatic glycogen synthesized by the direct pathway increased in both groups in the third and fourth hours after breakfast, but remained lower in glucokinase-deficient subjects than in controls, although not significantly different. The mechanisms controlling the contributions of the direct and the indirect pathways to hepatic glycogen synthesis are not fully understood, but the preferential utilization of the gluconeogenic pathway may result at least in part from the lower insulin/glucagon ratio observed in glucokinase-deficient subjects after breakfast (30). If this is so, the insulin secretory defect presented by these subjects would help to attenuate the hepatic effect of the mutation, by increasing the contribution of the gluconeogenic pathway to net hepatic glycogen synthesis. Whatever the mechanism responsible for the relative increased flux through the gluconeogenic pathway, this effect partially explains the mildness of the defect of net hepatic glycogen synthesis observed in these subjects. Finally, it is also possible that increased hepatic glycogen cycling may be partly responsible for the lower rates of net hepatic glycogen synthesis in the glucokinase-deficient subjects. In recent studies we have observed that hepatic glycogen synthase and glycogen phosphorylase can be simultaneously active in humans under conditions of net glycogen synthesis resulting in glycogen cy- 
cling $(30,31)$. The consequences of these GCK mutations on hepatic glycogen turnover remain to be determined.

Because most of the glucose that is taken up by the liver after a meal is converted to hepatic glycogen (32), any decrease in net hepatic glycogen synthesis would be expected to exacerbate postprandial hyperglycemia. Thus, the finding of defective hepatic glycogen synthesis may have important clinical consequences for glucokinase-deficient subjects. Indeed, we have observed that $65 \%$ of a cohort of 101 glucokinase-deficient subjects classified as having overt diabetes mellitus according to the World Health Organization definition (fasting plasma glucose $>7.8 \mathrm{mM}$ or $2 \mathrm{~h}$ after oral glucose load plasma glucose $>11.1 \mathrm{mM}$ [20]), fulfilled the 2-h criteria only and presented fasting plasma glucose $<7.8 \mathrm{mM}$ (Velho, G., and P. Froguel, unpublished results). Thus, decompensation in postprandial hyperglycemia rather than an increase in the fasting plasma glucose concentration is associated with the transition from impaired glucose tolerance to overt diabetes mellitus in these subjects. Normal glucose tolerance after a meal also depends on normal suppression of hepatic glucose production (33). In this regard increased relative rates of gluconeogenesis observed after a meal in the glucokinase-deficient subjects while probably beneficial in terms of hepatic glycogen repletion, is also likely an important contributing factor to postprandial hyperglycemia in these subjects. In support of this, we have observed abnormal suppression of hepatic glucose production by physiological levels of insulin $(252 \pm 27 \mathrm{pM})$ during an euglycemic clamp in a small number of glucokinase-deficient subjects (34). Taken together, these observations underscore the key role of the liver in the pathophysiology of hyperglycemia associated with glucokinase deficiency.

Data in the literature regarding hepatic glycogen synthesis in diabetic or nondiabetic subjects are scarce. The mildness of the hepatic glycogen synthesis defect in glucokinase-deficient subjects contrasts with the profound defect observed with a similar protocol in subjects with insulin-dependent diabetes, whose glycogen stores $4 \mathrm{~h}$ after dinner were only $30 \%$ of those of controls (20). On the other hand, the heterozygous disruption of GCK in transgenic mice results in mild pancreatic and hepatic defects (27) similar to those observed in our patients. During an hyperglycemic-hyperinsulinemic clamp, the reduction in hepatic glucose production in transgenic animals was only $65 \%$ of what was observed in wild-type animals. Furthermore, the relative contribution of the direct pathway to the synthesis of hepatic UDP-glucose was significantly lower in the heterozygous mice (39\%) as compared to the wild-type animals $(53 \%)$. Homozygous disruption of GCK in transgenic mice results in perinatal death with severe hyperglycemia and significant reduction in liver glycogen stores (28). Interestingly, expression of the glucokinase gene in $\beta$-cells in the absence of expression in the liver is sufficient for survival.

In conclusion, mutations in the coding regions of GCK are associated with decreased net accumulation of hepatic glycogen and augmented hepatic gluconeogenesis after meals. The former abnormality probably results from impaired glucose phosphorylation in hepatocytes due to decreased enzymatic activity of mutant glucokinase. Both abnormalities may contribute to postprandial hyperglycemia. These results indicate that the hyperglycemia of glucokinase-deficient NIDDM results from primary abnormalities of glucose metabolism in both the pancreatic $\beta$-cells and the liver.

\section{Acknowledgments}

We would like to thank the nurses and staff of the Yale New Haven Hospital General Clinical Research Center for their help in performing these studies and Veronika Walton for technical assistance.

This work was supported by grants RO1 DK-49230, PO1 DK45735, M01 RR-00123 from the United States Public Health Service Lipha Pharmaceutics (Lyon, France), and a grant from the Juvenile Diabetes Foundation, Intl. (G.I. Shulman).

\section{References}

1. Froguel, P., H. Zouali, N. Vionnet, G. Velho, M. Vaxillaire, F. Sun, S Lesage, M. Stoffel, J. Takeda, P. Passa et al. 1993. Familial hyperglycemia due to mutations in glucokinase: definition of a subtype of diabetes mellitus. $N$. Engl. J. Med. 328:697-702.

2. Hager, J., H. Blanché, F. Sun, N.V. Vaxillaire, W. Poller, D. Cohen, P. Czernichow, G. Velho, J.J. Robert, N. Cohen et al. 1994. Six mutations in the glucokinase gene identified in MODY using a nonradioactive sensitive screening technique. Diabetes. 43:730-733.

3. Stoffel, M., P. Froguel, J. Takeda, H. Zouali, N. Vionnet, S. Nishi, I.T. Weber, R.W. Harrison, S.J. Pilkis, S. Lesage et al. 1992. Human glucokinase gene: isolation, characterization, and identification of two missense mutations linked to early-onset non-insulin-dependent (type 2) diabetes mellitus. Proc. Natl. Acad. Sci. USA. 89:7698-7702.

4. Sun, F., B. Knebelmann, M.E. Pueyo, H. Zouali, S. Lesage, M. Vaxillaire, P. Passa, D. Cohen, G. Velho, C. Antignac et al. 1993. Deletion of the donor splice site of intron 4 in the glucokinase gene causes maturity onset diabetes of the young. J. Clin. Invest. 92:1174-1180.

5. Vionnet, N., M. Stoffel, J. Takeda, K. Yasuda, G.I. Bell, H. Zouali, S. Lesage, G. Velho, F. Iris, P. Passa et al. 1992. Nonsense mutation in the glucokinase gene causes early-onset non insulin dependent diabetes mellitus. Nature (Lond.). 356:721-722.

6. Zouali, H., M. Vaxillaire, S. Lesage, M. Vaxillaire, P. Passa, D. Cohen, G. Velho, C. Antignac et al. 1993. Linkage analysis and molecular scanning of the glucokinase gene in NIDDM families. Diabetes. 42:1238-1245.

7. Matschinsky, F.M. 1990. Glucokinase as glucose sensor and metabolic signal generator in pancreatic beta-cells and hepatocytes. Diabetes. 39:647-652.

8. Matschinsky, F., Y. Liang, P. Kesavan, L. Wang, P. Froguel, G. Velho, D. Cohen, M.A. Permutt, Y. Tanizawa, T.L. Jetton et al. 1993. Glucokinase as pancreatic beta-cell glucose sensor and diabetes gene. J. Clin. Invest. 92:2092-2098.

9. Gidh-Jain, M., J. Takeda, L.Z. Xu, A.J. Lange, N. Vionnet, M. Stoffel, P. Froguel, G. Velho, F. Sun, D. Cohen et al. 1993. Glucokinase mutations associated with non insulin dependent (type 2) diabetes mellitus have decreased enzymatic activity: implications for structure/function relationships. Proc. Natl. Acad. Sci. USA. 90:1932-1936.

10. Takeda, J., M. Gidh-Jain, L.Z. Xu, P. Froguel, G. Velho, M. Vaxillaire, D. Cohen, F. Shimada, H. Makino, S. Nishi et al. 1993. Structure/Function studies of human glucokinase: enzymatic properties of sequence polymorphism, mutations associated with diabetes, and other site-directed mutants. J. Biol. Chem. 268:15200-15204.

11. Sturis, J., I.J. Kurland, M.M. Byrne, E. Mosekilde, P. Froguel, S.J. Pilkis, G.I. Bell, and K.S. Polansky. 1994. Compensation in pancreatic beta-cell function in subjects with glucokinase mutations. Diabetes. 43:718-723.

12. Byrne, M.M., J. Sturis, K. Clément, N. Vionnet, M.E. Pueyo, M. Stoffel, J. Takeda, P. Passa, D. Cohen, G.I. Bell et al. 1994. Insulin secretory abnormalities in subjects with hyperglycemia due to glucokinase mutations. J. Clin. Invest. 93:1120-1130.

13. Velho, G., P. Froguel, K. Clément, M.E. Pueyo, B. Rakotoambinina, H. Zonali, P. Passa, D. Cohen, and J.J. Robert. 1992. Primary pancreatic beta-cell secretory defect caused by mutations in the glucokinase in kindreds of maturity onset diabetes of the young. Lancet. 340:444-448.

14. Rothman, D.L., I. Magnusson, L.D. Katz, R.G. Shulman, and G.I. Shulman. 1991. Quantitation of hepatic glycogenolysis and gluconeogenesis in fasting humans with ${ }^{13} \mathrm{C}$ NMR. Science (Wash. DC). 254:573-576.

15. Magnusson, I., D.L. Rothman, L.D. Katz, R.G. Shulman, and G.I. Shulman. 1992. Increased rate of gluconeogenesis in type II diabetes mellitus. A ${ }^{13} \mathrm{C}$ nuclear magnetic resonance study. J. Clin. Invest. 90:1323-1327.

16. Shulman, G.I., G. Cline, W.C. Schumann, V. Chandramouli, K. Kumaran, and B.R. Landau. 1990. Quantitative comparison of pathways of hepatic glycogen repletion in fed and fasted humans. Am. J. Physiol. 259:E335-E341.

17. Fajans, S.S. 1990. Scope and heterogeneous nature of MODY. Diabetes Care. 13:49-64.

18. WHO Study Group on Diabetes Mellitus. Report. Tech. Rep. Ser. WHO. Geneva World Health Org. 1985.

19. Tchobroutsky, G. 1991. Blood glucose levels in diabetic and non diabetic subjects. Diabetologia. 34:67-73. 
20. Hwang, J.H., G. Perseghin, D.L. Rothman, G.W. Cline, I. Magnusson, K.F. Petersen, and G.I. Shulman. 1995. Impaired net hepatic glycogen synthesis in insulin-dependent diabetic subjects during mixed meal ingestion. ${ }^{13} \mathrm{C} \mathrm{nu}-$ clear magnetic resonance spectroscopy study. J. Clin. Invest. 95:783-787.

21. Haase, A., J. Frahm, D. Mattaei, W. Häniche, and K.D. Merboldt 1986. FLASH imaging. Rapid NMR imaging using low flip-angle pulses. J. Magn. Reson. 67:258-266.

22. Ordidge, R.J., J. Connelly, and A.B. Lohman. 1986. Image-selected in vivo spectroscopy (ISIS): a new technique for spatially NMR spectroscopy. $J$. Magn. Reson. 66:283-294.

23. Silver, M., R. Joseph, C. Chen, V. Sank, and D. Hoult. 1984. Selective population inversion in NMR. Nature (Lond.). 310:681-683.

24. Wolfe, R.R. 1992. Radioactive and stable isotope tracers in biomedicine: principles and practice of kinetic analysis. Wiley-Liss, New York. 417-438.

25. Magnuson, M.A., and K.D. Shelton. 1989. An alternate promoter in the glucokinase gene is active in the pancreatic beta-cell. J. Biol. Chem. 264:1593615942 .

26. Iynedjian, P.B., P.R. Pilot, T. Nouspikel, J.L. Milburn, C. Quade, S. Huges, C. Ucla, and C.B. Neugard. 1989. Differential expression and regulation of the glucokinase gene in liver and islets of Langerhans. Proc. Natl. Acad. Sci. USA. 86:7838-7842.

27. Bali, D., A. Svetlanov, H.W. Lee, D. Fusco-DeMane, M. Leiser, B. Li, N. Barzilai, M. Surana, H. Hou, N. Fleischer et al. 1995. Animal model for maturity-onset diabetes of the young generated by disruption of the mouse glu- cokinase gene. J. Biol. Chem. 270:21464-21467.

28. Grupe, A., B. Hultgren, A. Ryan, Y.H. Ma, M. Bauer, and T.A. Stewart 1995. Transgenic knockouts reveal a critical requirement for pancreatic beta cell glucokinase in maintaining glucose homeostasis. Cell. 83:69-78.

29. Terauchi, Y., H. Sakura, K. Yasuda, K. Iwamoto, N. Takahashi, K. Ito, H. Kasai, H. Suzuki, O. Ueda, N. Kamada et al. 1995. Pancreatic beta-cell-specific targeted disruption of glucokinase gene: diabetes mellitus due to defective insulin secretion to glucose. J. Biol. Chem. 270:30253-30256.

30. Roden, M., G. Perseghin, K.F. Petersen, J. Hwang, G.W. Cline, K. Gerow, D.L. Rothman, and G.I. Shulman. 1996. The roles of insulin and glucagon in the regulation of hepatic glycogen synthesis and turnover in humans $J$. Clin. Invest. 97:642-648.

31. Magnusson, I., D.L. Rothman, B. Jucker, G.W. Cline, R.G. Shulman, and G.I. Shulman. 1994. Liver glycogen turnover in fed and fasted humans. Am. J. Physiol. 266:E796-E803.

32. Moore, M.C., A.D. Cherrington, G. Cline, M.J. Pagliassotti, E.M. Jones, D.W. Neal, C. Badet, and G.I. Shulman. 1991. Sources of carbon for hepatic glycogen synthesis in the conscious dog. J. Clin. Invest. 88:578-587.

33. DeFronzo, R.A., R.C. Bonadonna, and E. Ferrannini. 1992. Pathogenesis of NIDDM: a balanced overview. Diabetes Care. 15:318-368.

34. Clément, K., M.E. Pueyo, M. Vaxillaire, B. Rakotoambinina, F. Thuillier, P. Passa, P. Froguel, J.-J. Robert, and G. Velho. 1996. Assessment of insulin sensitivity in glucokinase-deficient subjects. Diabetologia. 39:82-90. 